\title{
Itacitinib Adipate
}

National Cancer Institute

\section{Source}

National Cancer Institute. Itacitinib Adipate. NCI Thesaurus. Code C158906.

The adipate salt form of itacitinib, an orally bioavailable inhibitor of Janus-associated kinase 1 (JAK1) with potential antineoplastic and immunomodulating activities. Upon oral administration, itacitinib selectively inhibits JAK-1, thereby inhibiting the phosphorylation of signal transducer and activator of transcription (STAT) proteins and the production of proinflammatory factors induced by other cytokines, including interleukin-23 (IL-23) and interleukin-6 (IL-6). The JAK-ST AT pathway plays a key role in the signaling of many cytokines and growth factors and is involved in cellular proliferation, growth, hematopoiesis, and the immune response; JAK kinases may be upregulated in inflammatory diseases, myeloproliferative disorders, and various malignancies. 